\title{
Contribution of Financial Literacy to Behavior
}

\author{
Ramesh Prasad Chaulagain \\ Kathmandu University, School of Education \\ Nepal Rastra Bank, Kathmandu, Nepal \\ chaulagainramesh@gmail.com
}

\begin{abstract}
Almost all the people around the world behave with money in daily lives whereas understanding how they behave is important. It is obvious that the education, which can not affect behavior of people, is worthless. Financial literacy also is believed to change financial behavior of individuals. Financial literacy implies two sides, i.e. concept and application of personal finance. The concept consists financial knowledge and basic skill of numeracy and financial decisions; the application consists the financial behavior. The focus of the article is to discuss how the financial literacy contributes financial behavior and thereby financial wellbeing of individuals. For this, the article presents a transmission mechanism of financial knowledge and skill to the financial behavior through a framework. However, there are some contexts, conditions and criterions to transmit the financial knowledge and skill into financial behavior and well-being. Moreover, categorizing the financial behavior of individuals is a significant issue in study of financial literacy. Particularly for the survey research, a new categorization and degree of the financial behavior is presented, which is ranked as good, moderate and weak financial behavior in comparative ways. The study establishes the relevancy of the evaluation criteria of financial behavior and also presents a framework on how the financial educations work/contribute in financial behavior.
\end{abstract}

Keywords: Financial literacy, financial behavior, financial well-being, transmission mechanism, personal finance

\section{Introduction}

Sometimes, financial education and financial literacy are interchangeably used though these are neither same nor isolated concepts. This section deals with some background and concepts on financial literacy. Understanding the financial literacy has two facets: conceptual and operational (Remund, 2010).The first one is about understanding the common and basic aspects of financial matters such as income, financial planning, budgeting, saving, borrowing, spending, and investing, whereas the second is about how the individuals behave with money and personal financial resources in their daily lives. The operational part of the financial literacy is more contextual in terms of person, time, and place. Personal financial resources are income and borrowing, other things remaining the same. Fraczek and Klimontowicz (2015) present another facet of financial literacy and education as financial capability. Financial capability is expressed synonymously as financial skill. It is about how rationally one can take financial decision and how efficiently allocate available limited financial resources, i.e. income and borrowing to achieve several life-needs. Financial literacy is the ability to understand finance (Ansong and Gyensare, 2012, p126). Typically, financial literacy considers the matter of personal finance rather than 'finance' as a whole. Similarly, merely understanding of the personal financial matter is only a part of financial literacy. The application of financial resources efficiently is a subsequent part of financial literacy. Ravikumar (2013) opines financial literacy as personal financial skill that affects financial well-being of individuals. However, he has left to mention how the well-being is achieved without any behavioral bridge between the literacy and well-being. Buckland (2010) defines financial literacy in both narrow and broader sense. In narrow sense, the individuals behave in normal, linear and normative way what they have learned regarding the financial matters. In broader sense, the individuals behave beyond the normality, be critical to the system about what is going on in financial market and what should be there, and about their rights from financial system, consider the socio-economic aspects of personal financial matters, be more active in increasing financial gains, take some financial risk for further benefit in some innovative ways, develop skill of negotiation in financial market and thereby optimize their economic welfare ultimately. 
Huston (2010) opines that financial literacy, financial education and financial knowledge are similar concepts. But, I argue that the financial education, knowledge and literacy are not the same concepts as he claims. However, the financial education is the source of financial literacy (Sucuahi, 2013) and the financial knowledge is one of the dimensions of financial literacy. Moreover, Scheresberg (2013) presents financial literacy beyond the financial education. But he is unable to present the evidence and argument behind this. I argue that financial literacy is an intermediate target of financial education, whereas the education is more than the literacy as well. The literacy is basic knowledge and skill that helps to achieve more scope of learning and increases the employability. Several studies and literature explain financial knowledge, skill, attitude, behavior and well-being within a circle. However, I argue that the financial education provides a set of financial knowledge and skill, which is expressed as financial literacy. In the next phase the literacy contributes to its application, i.e. how persons apply their knowledge and skill into practice, other things remaining the same. There is a wide gap between behavior and well-being. Hence the behavior is about how rationally the individuals behave as their knowledge, skill and other circumstances. The well-being is the destination of the behavior. In other words, financial literacy is an important predictor of financial behavior (Scheresberg, 2013, p1). Moreover, Buckland (2010) believes on a functional version of financial literacy, i.e. financial knowledge and skill have a functional relationship with financial position or well-being. However, without proper financial behavior, the well-beings are not achieved that directly. Shortly, Most of the previous works on financial literacy conclude on positive association of financial literacy of individuals with their financial behavior. But non-of the available studies are able to present a clear mechanism or path about how the financial literacy really works? Additionally, most of the studies talk and mention about measuring and explain financial behavior this and that way; however there is gap of proper, empirical and data based categories and evaluation of financial behavior about how to understand what the people do with their money and financial literacy.

\section{Dimensions of Financial Literacy}

Commonly, there are four dimensions of financial literacy, i.e. financial knowledge, skill, attitude and behavior. However, the first two are basic and the latter two are gradual dimensions. This section discusses about dimensions of financial literacy. Additionally, financial well-being is understood as the destination of financial behavior. Financial knowledge is about the information, awareness and understanding of financial matters. Financial skill is about how the individuals take financial decision, how they take a purchase decision, how they negotiate for the purchasing and consuming financial services, how they calculate interest, charges, taxes, discounts and penalties on saving and borrowing. Conceptually, the financial knowledge and skill make financial literacy in primary level. Moreover, financial attitude is psychological judgment of individuals about financial services and service providers. The judgments are positive, negative, passive and/or indifferent towards the financial matters, service providers and financial behavior as well. The next dimension is about how the individuals behave with money in their regular lives, i.e. financial behavior. However, financial well-being is also considered as a new dimension of financial literacy.

Australian Securities and Investments Commission (2014), Organization for Economic Cooperation and Development (2005), Carpena, Cole, Shapiro and Zia (2011) and Atkinson and Messy (2012) present four dimensions of financial literacy, i.e. financial knowledge, financial skill, financial attitude and financial behavior of individuals. Lusardi and Mitchell (2014) have mentioned financial knowledge, numeracy and planning skill and financial behavior as the financial literacy dimensions. She has left the role of attitude formation in financial literacy; however attitude and intention are linked with financial behavior. According to the behavioral theories, the behavior of individuals is more or less subject to change with psychological function of individuals towards any activities. Numeracy and financial planning, she has mentioned, are also the parts of financial skill. However, Program for International Student Assessment (2012) has added financial well-being as a new dimension of financial literacy. Xu and Zia (2012) mention financial literacy and behavior as two major dimensions. They have further explained financial knowledge and skill are integrated as financial literacy and financial behavior as the impact of financial literacy. Financial awareness itself is not a different dimension; it is a part of financial knowledge. Additionally, some studies express financial awareness, financial understanding, and financial consciousness as the financial knowledge. Synonymously, financial ability, confidence, capability, decision making are similar to financial skill. Financial skill is a personal capability in financial matters and calculations as well. Next is about financial attitude, which is 
about how the peoples are psychologically guided. Financial literacy, i.e. knowledge and skill sometimes can affect the financial attitude of individuals and sometimes not. The financial behavior is a financial practice that is guided by financial culture and several other variables as well, not only by financial literacy and attitude. Very few authors have argued about financial well-being as a different dimension of financial literacy, hence it is a long term effect of financial literacy, behavior and other situational factors. However, all of the available studies are unable to show a linear path how the dimensions are interrelated to each other and/or how one dimension contributes another. Similarly, it is also practical that stepping from one dimension to another is only possible with some assumptions and time lags as well. Such assumptions and time lags are time, context and priority specific of the individuals.

Indicators of Financial Behavior: Understanding, measuring, and evaluating financial behavior of individuals is important but a difficult task. There are three basic difficulties in this: first, usually the people desire to make secret of their financial activities; second, there is scaling limitation about the financial behavior of individuals whether their financial behavior is right/wrong and/or good/bad; and third is about lack of unanimous measuring and categorizing tools of behavior as well. This section deals with some of the indicators to explore and explain the financial behavior of the individuals. These indicators show and indicate how the individuals are using their money and personal financial resources. The indicators presented here are supposed to be useful in both qualitative and quantitative studies. The section also presents a category of scaling the financial behavior of individuals that helps the researchers to reflect the behavior in comparative and calculative ways.

Lyons (2005) mentions saving, credit, wealth accumulation, investment, negotiation in shopping, making household budget, periodic review of saving/credit report, home ownership and making financial plan are some of indicators of financial behavior of persons. Dew and Xiao (2011) have presented cash flow management, saving and investments, credit and insurance as the indictors of financial behavior. Hastings, Madrian and Skimmyhorn (2013) have presented retirement planning, saving, investing and wealth accumulation as indicators of financial behavior. The indicators of financial behaviors: saving; planning for retirement; absence of debt; stock ownership and investment decisions; cash flow management; activity in retirement plans; and financial inertia such as choice of default options and payment of unnecessary fees (Fernandes, Lynch and Netemeyer, 2014, p6). Robb and Woodyard (2011) opine that cash/credit management, emergency savings, retirement plan, risk management and state planning are indicators of financial behavior of persons. Xu and Zia (2012) have mentioned financial record keeping, borrowing and investing, improve in business practice, asset accumulation, revenue mobilization through tax collection are some of the financial behavioral indicators. All the references per se present similar activities as the indicators of financial behavior that have more similarities in showing how the individuals behave with money and personal financial resources. Normally, income and borrowings from other sources are treated as personal financial resources that are expected to be utilized in productive sector, i.e. income generating activities. Common indicators of financial behavior are saving, borrowing, investing, budgeting, planning, financial record keeping, identifying and managing financial risk, purchasing and selling financial instruments and making purchasing decisions in regular lives etc. Still the question remains important of how financial behavior is to categorize for comparing, evaluating and calculating the financial activities of individuals. Most of the literature and studies mention that financial behavior is important to measure but there is a gap to explain what categories of those activities represent clear, flexible and comparable categories.

Xiao, Chen and Chen (2013) and Agarwalla, Barua, Jacob and Varma (2012) have presented two scales to indicate the financial behavior of individuals, i.e. negative or undesirable and positive or desirable. They further argue that the positive behavior contributes to better financial well-being and satisfaction and viceversa. However, they are unable to categorize the in-between nature of financial behavior which seems difficult to say neither positive nor negative in particular period of time. And also to understand the negative behavior is quite difficult in their studies, however they have fail to mention what financial behaviors are either positive or negative. Similarly, such extreme judgment of financial behavior of others as positive and/or negative can create a confusion sometimes. Some examples of positive and desirable financial behavior of individuals are: spending in consumption below personal income, promoting regular saving, wise use of credit, regular assessment of credit utilization, making budget (a projection of personal income and expenditure for the future), seeking and following financial advices and counseling, wise investment decision, 
family discussion and decision in financial matters, paying the utility bills timely, serving the credit properly, portfolio diversification for minimizing financial risk, timely reviewing the financial position of individuals etc.

Some of indicators of financial behavior according to Hogarth, Beverly and Hilgert (2003) are cash flow management, regular saving, investment activities, proper credit utilization, account ownership, asset accumulation etc. They have further categorized the financial behavior of individuals into high, medium and low. They have scaled 25 percent and below financial behavior score as low, 25-70 percent as medium and above 70 percent score as high financial behavior. Still, they are unable to explain how to understand the 'high' financial behavior whether as good, very good, or best or anything else. Actually, high and low seems unconformable evaluation of financial behavior of people. Such scoring practice of financial behavior in percentage basis is also criticized as ad hoc practice in measurement. Additionally, Atkinson and Messy (2012) and Organization for Economic Cooperation and Development, International Network of Financial Education (2012) have categorized the financial behavior tying with financial literacy. According to them, those are financially literate who keep the financial records properly, check the personal financial records actively and regularly, pay the bill timely, and use credit cards etc. Here the new problem may arise with this analysis when the researcher desires to see the causal relationship of financial literacy with financial behavior. Another, some behaviors are not so good, and not so weak, that is not mentioned in the categorization per se. If the behavior is not classified with some basis and categories, the relationship seems difficult to establish. Therefore, I argue that the categorization of financial behavior of the individuals is better to categorize into good or satisfactory, weak or very less satisfactory and moderate.

\section{Theoretical Lens in Financial Behavior}

Human behavior is influenced by several factors and situation. Behavior explains about how the individuals act and behave within a certain circumstances in particular time. This section discusses some theoretical lens to see what are the factors that are affecting the human behavior and then link it with how one behave with money and personal financial resources. Two approaches, basically, are considered in this study to discuss; one is social learning theory propounded by Albert Bandura and another one is the theory of planned behavior developed by Icek Ajzen. Ajzen (1991) has discussed that person's intention (motivation), ability, attitude, subjective norms, self-regulation, resources, opportunities, personality traits and perceived behavioral control factors are major determinants of behavior. Australian Securities and Investment Commission (2011) has mentioned that the knowledge merely is not enough to affect one's financial behavior.

Shim, Barber, Card, Xiaoand Serido (2009) have mentioned about consumer financial socialization according to which, the financial knowledge, skill, attitude and behavior of individuals or adolescence are influenced by parents, school and working place. They further mentions that the financial behavior of individuals is affected with three attitudinal factors, i.e. attitude towards financial matters and behavior, subjective financial norms and perceived financial control behavior. Moreover, financial behavior of individuals is also influenced by mass media, economic condition of country and level of financial need of them as well. Behavior is affected by how individuals think and evaluate about financial matters, i.e. how individuals make priority of their behavior. For example, if someone is financially aware about default of loan that may result the loose of collateral property according to the law, s/he tries to pay the installment of borrowing timely and properly. Additionally, Shim, Barber, Card, Xiao and Serido (2009) advocate theory of planned behavior, the psychological and/or attitudinal factors are major contributors in human financial behaviors. Here, the attitude is a psychological factor about thinking and evaluating the financial matters and system as a whole by each financial consumer. The attitude is affected by one's financial knowledge, while other things remain the same. Attitude is understanding, perception and mind make up of something that affect one's activities and behavior. For e.g. if I am satisfied with the future usefulness of saving, I start to save and make it continue and vice-versa. In short, theory of planned behavior links how financial literacy contributes the financial behavior. Similarly, perceived behavioral control is related to normative limitation of understanding of individuals. Individuals understand and perceive some financial activities from their parents, schools and others in society and they behave accordingly. They sometimes control and sometimes promote their behavior with their perceived knowledge and subjective understanding rather objective knowledge as well. 
Behavior of individuals, according to social learning theory of Bandura (1971) is mainly affected by experience, knowledge, observation, demonstration effects, fear and safety consciousness, greed and future expectation, motivation towards financial benefits, awareness and consciousness on particular matters, attraction/promotion of behavior etc. Financial experience of past, may affect financial behavior of today because the individuals usually tries to follow what they have done before which is also depends on financial culture. Financial culture is how the individuals are living in financial circumstances for a long. Financial knowledge on financial matters and system, observation and demonstration effects are some of important variables to affect one's financial behavior. People follow or copy what others do is a normal phenomenon in financial activities too. Similarly, Fear and safety consciousness, greed and future expectation, motivation towards financial benefits, awareness and consciousness on particular matters, attraction/promotion are some other variables to affect one's financial behavior. For e.g. if I think that my financial future is safe with my saving, then I start/continue to save and vice-versa. Similarly, if I think that the future rate of rerun will be high in saving or investing, I will save or invest with its future expectation. Motivation is also important in financial behavior. Motivation has two facets, positive motivation for expectation, gain and attraction whereas negative motivation for fear of loss, damage, downsize etc. Likewise, awareness and consciousness of someone towards financial matters and system make more intimate in financial behavior. Awareness and consciousness is also close to knowledge and understanding. If someone is aware of financial risk/return, cost/benefits and opportunity cost of financial gain, his/her financial behavior differs. Risk is about doubtful situation of saving/investment in one financial institution and the benefit is the assurance and consistency of the interest rate provided by the financial institutions. It is obvious that, no one is motivated to save/invest their life-earning in doubtful and unsecured financial institutions. Normally, people follow lower risky, higher returning, low cost and higher benefit financial matters in their lives, comparatively. Correspondingly, attraction and promotional activities are also the factor affecting one's financial behavior. If the people are made aware of financial benefits from financial investment, they will be motivated towards it and vice-versa. In short, financial behavior is primarily affected by psychological factors such as attitude, perception, financial norms, and situational factors as well. According to the theories, behavior is not an absolute and isolated matter, it is contextual as well.

Contribution of Financial Literacy to Behavior: Does financial literacy make a difference, if yes, how? According to the findings of several previous studies, the financial literacy contributes financial behavior of individuals. Similarly, what makes or produces financial literacy in practice and how the financial literacy transmits to financial behavior are interrelated concerns each other. To show a path or channel between financial literacy and behavior, a transmission mechanism is appropriate to demonstrate. Transmission mechanism is about how an intervention helps to achieve the aim of intervention and/or a structure to present how financial literacy contributes financial behavior. This section discusses and demonstrates how the financial literacy contributes financial behavior. Proposed model or a graphical presentation that has five gradual phases: education (as input), financial literacy that consists of knowledge and skill (as output), financial attitude and behavior (as outcome), and financial well-being (as impact). How the financial literacy (a combination of financial knowledge and skill) contributes financial behavior is demonstrated through the following conceptual framework. The proposed framework also requires 3 Cs; i.e. context, conditions/assumptions and criterions to satisfy the achievement or target. The framework is a consolidated idea of previous studies containing education, literacy, behavior and well-being.

There are three different findings and claims of previous research and studies that financial literacy contributes financial behavior significantly, financial literacy contributes financial behavior moderately and financial literacy does not contribute financial behavior at all. Lusardi, Mitchell and Curto (2010) and Scheresberg (2013) argue that financial literacy is a strong predictor and contributor of financial behavior of individuals. However, Mandell and Klein (2009), Tisdell, Taylor and Forte (2013), Carpena, Cole, Shapiro and Zia (2011) and Forte (2012) have found a poor contribution of financial literacy on financial behavior. But, they do not diagnose the reason of the poor effects further. All of these findings show that peoples do not always necessarily behave according to their financial awareness, skill and attitude. However, it is also not necessary that all the studies find the positive contribution of financial knowledge and skill in financial behavior. Some measuring styles, level of participants and also may vary the findings. Several studies provided evidence of a link between knowledge and behavior, though they vary in how knowledge is measured and what behaviors are addressed (Robb and Woodyard, 2011, p61). Moreover, Monticone (2010) 
has double barrel opinion about the relationship between financial literacy and behavior that the financial literacy contributes financial behavior and also sometimes the financial behavior affects financial literacy; however the double barrel argument is required to be justified further how the behavior affects financial literacy. He has further argued that the past financial behavior teaches the knowledge to the individuals and again that affects to the future behavior, but he has left to mention what factors affect the past financial behavior actually. I argue that the past behavior are affected by family, peers, schools, Medias and community etc. However he has also left to mention that the financial education does not merely contributes to gain financial knowledge; it also provides financial skill as well. Similarly, the knowledge has the effects in financial attitude of individuals and thereby the behavior, according to the theory of planned behavior.

Financial education can help individuals gain financial knowledge and that financial knowledge is linked to financial behavior (Collins, 2010, p13). It shows that the financial education is one of sources of financial literacy. Fatoki and Oni (2014) argue that the financial literacy contributes financial behavior of individuals through saving, borrowing, investment, and retirement planning and portfolio choices. Here they have connected financial behavior through particular financial indicators; however there are other several indicators as well. Fernandes, Lynch and Netemeyer (2014), Robb and Woodyard (2011) also believe in stronger association between financial literacy and behavior. They have ignored the contribution of financial attitude in financial behavior; however, the financial literacy includes financial knowledge and skill. According to Agarwalla, Barua, Jacob and Varma (2015), attitude towards money and finance, and financial knowledge affect financial behavior of individuals; however they have also left the contribution of financial skill in financial behavior. They show a contribution of financial attitude in financial behavior. Further, there is a positive association between financial attitude and behavior (Atkinson and Messy, 2012). Selcuk (2015) has also found a positive contribution of financial knowledge and attitude in the financial behavior of participants where they have mentioned timely payment of bill, making personal financial budget and saving activities as the financial behavior. However, they have also left the contribution of financial skill in the financial behavior of individuals. Moreover, Willis (2013) presents a correlation between financial education and financial knowledge, between financial and financial behavior but weak relationship between financial education and financial well-being. There are two parts of this argument: the education itself is necessary but not sufficient to influence one's financial well-being. Next, education does not mean only the formal education what we have conceptualized. Professor Parajuli (2013) challenges to traditional understanding of merely the formal source of education is sufficient and further opine to accept and prioritize multiple forms of learning and knowledge gain that comes from the experience, culture and tradition too.

Consumer Financial Protection Bureau (2015) also mentions that the financial literacy has direct role in financial well-being of individuals where the well-being is defined as control over the regular personal financial activities, self-confidence or self-efficacy, financial capacity to cope the financial shock, following right path of obtaining financial goal, and enjoying financial security and autonomy. Similarly, the bureau has also presented that a hierarchy of financial education contributes financial knowledge and skill that contribute financial behavior and thereby financial well-being. Here the financial attitude and financial intention to bridge the financial knowledge and skill with financial behavior are missing. However, the ways of achieving financial well-being through financial literacy is not clearly mentioned. The traditional beliefs on financial well-being about measurable financial wellness of individuals has been changed these days. The present wellbeing concept has changed to material and non-material aspects of a person's perception from their financial status, improving their living standards and includes perceptions such as: ability to meet the needs, feeling safe, feeling comfortable and satisfied with the income and the award distribution system (Taft, Hosein, Mehrizi, and Roshan, 2013, p65). Financial behavior has the effects to financial well-being of individuals (Dew and Xiao, 2011, p44).

Almost the literature and previous studies have three major claims on financial literacy and its effects: first, the financial education contributes financial literacy that includes financial knowledge and skill; second, financial literacy contributes financial attitude and behavior; third, financial attitude and behavior contributes financial well-being. However, some studies claim that the financial literacy contributes financial well-being also. Furthermore, financial education is one of the major sources of financial literacy that again contributes financial attitude and behavior and thereby financial well-being. In practice, all the claims made per se are based on some assumptions and conditions to fulfill. But, none of the available studies have clearly explained 
how the financial literacy transmits to financial behavior and thereby financial well-being in a single demonstration. Financial education has a primary target to improve financial knowledge and skill, improve in financial behavior as a gradual target and improve in financial well-being as an ultimate target. On the basis of above mentioned literature and studies, I have presented a framework of transmission mechanism of financial literacy to financial behavior and thereby the financial well-being. In the beginning part of the framework/model, financial education is input to make the individuals financially knowledgeable and skilled. Here, the financial knowledge and skill that the people gain from several possible educational sources is the desirable situation and alternatively said financial outputs. Financial education is not an absolute concept and is also affected by several other contexts and preconditions. Some of the preconditions are political/legal, technological, rival situation of education providers, financial resource limitations, policy constraints and sociological aspects. Here, the financial knowledge and skill are the output variables that are under control of education providers. Some of the sources of such education are mass Medias, formal education, family, peer, neighbors, observation visits and audio-visual aids etc.

In the next stage, the knowledge and skill on financial matters and financial market in total, make individuals financially literate, thereby it contributes financial attitude and thereby financial behavior. Financial attitude and behavior are attributed as outcome variables which are expected or desired situation of intervention in terms of financial literacy. I argue that the output variables convert into financial outcome variables subject to positive effort of individuals. In the gradual stage, the financial literacy (knowledge and skill) contributes financial behavior via financial attitude and sometimes directly. This outcome situation is not fully under direct control of intervention or financial education, however the intervention can only to expect the desired situation. Outcomes from the particular outputs are achieved when the people themselves act accordingly. Dahal and Uprety (2015) describe output as expected results or deliverables, outcome as only accountability of intervention and impact as effect in people's well-being. They have also described these three variables, i.e. output, outcome and impact as a hierarchy of change that comes from particular interventions with some conditions and assumptions. They have further argued that these variables are linear but not necessarily the proportional due to unequal time lag between one to another phase. Normally, the situation or the outcome is out of accountability of intervention. Final stage of this model says that when the behavior contributes the well-being of individuals, the impact or the well-being is expected to be sustainable for the long-run.

The proposed model/frame does not only explain how the output (financial knowledge and skill) contributes outcome (financial attitude and behavior) but also the outcomes are affected by other factors as control variables. The control variables to work in this model may be several, some of them are; income of people, availability of proper financial services, propensity to consume and save, inflation, market interest rate, financial culture, economic situation and demographic variables etc. Affecting the financial outputs is an intermediate target of financial interventions and change in financial outcomes or behavior positively is the ultimate targets. The major argument of the model is if a person is financially educated, his/her stock of financial knowledge and skill is expected to increase. Secondarily, if the person behave according to the knowledge and skill, his/her financial well-being is expected to be better-off, other things remaining the same.

Figure 1: Transmission Mechanism of Financial Literacy to Behavior

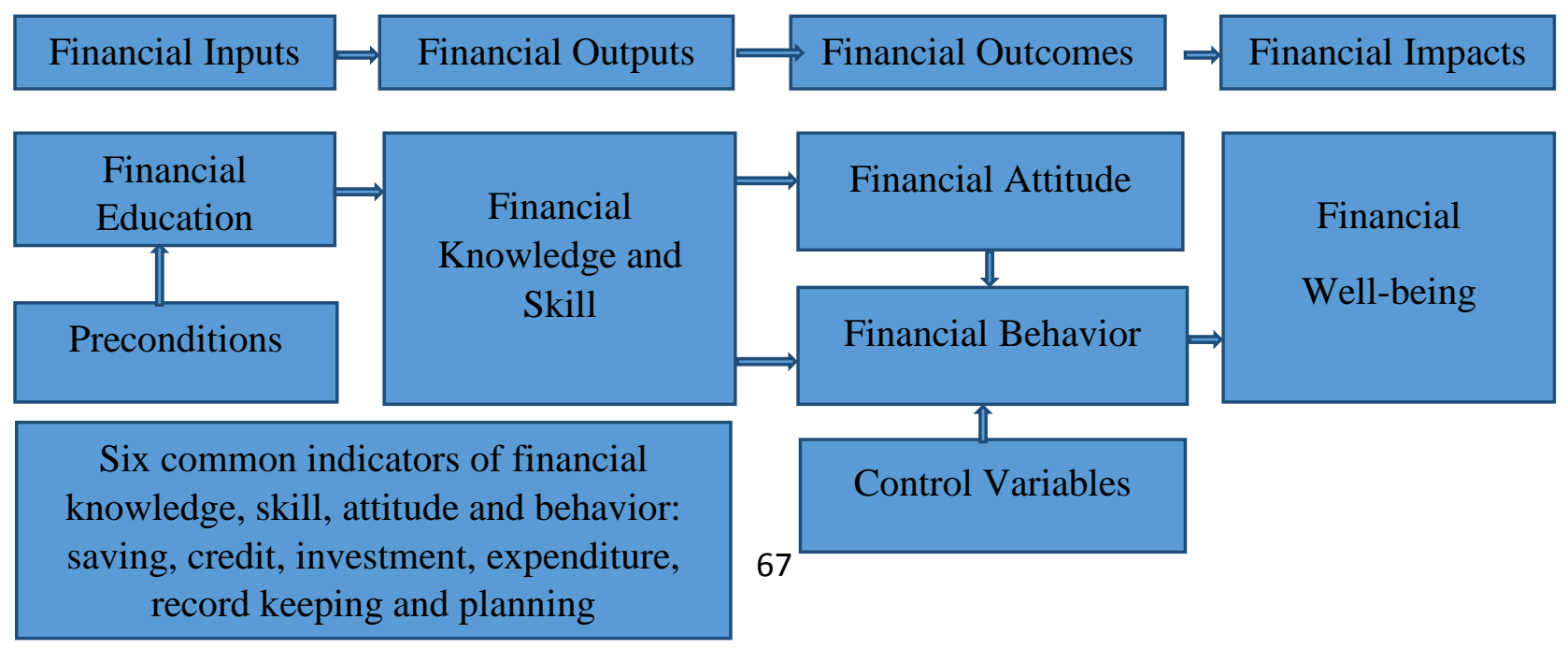




\section{Conclusion and Implications}

Financial literacy is a contemporary personal financial issue that concerns how the persons understand and behave with money, income and personal finance. There are four common financial literacy dimensions, i.e. financial knowledge, skill, attitude and behavior, however financial well-being is an ultimate destination of the financial understanding and behavior. Financial literacy is not same for all. It is different for male/female, rich/poor, educated and uneducated, different age group, employed and unemployed, rural urban people and also country to country. The conceptual understanding on financial literacy in one economy may not exactly the same with another economy. Lusardi and Mitchell (2014) and Hogarth, Beverly and Hilgert(2003) deny the one-size-fits-all approach of financial education to achieve expected behavioral change in financial matters, it is because the priority, demand, context, gender, age, education, background and socio-economic status of individuals are different. So, there is required a right financial literacy for right persons in right manner in right place in right way. As a significant dimension of financial literacy, it is quite difficult task for the researchers to understand and measure the financial behavior. Additionally, understanding the financial matters and skill is required to convert into behavior. People are doing their financial activities knowingly and unknowingly and sometimes partially knowingly as well. It is therefore, not all the financial behavior is guided by knowledge and kill, sometimes with experience, expectations and motivations as well. According to the behavior theories, most of the financial behavior depends on the situation, terms and conditions of institutions, need and priority of the individuals and several other factors as well. Similarly, the financial behavior of individuals can be seen with how they earn, spend, save, invest, borrow and utilize their financial resources in daily lives. I conclude my study to discuss with some of findings, raising some of issues related to the financial literacy and providing some implications.

The several studies have directed towards justifying that the financial literacy contributes financial behavior. I find that financial literacy is basically a behavioral issue in financial matters. Financial matters are based on how the individuals understand and behave with money and personal financial resources. Personal financial resources are, basically the personal income and borrowings from the others. Understanding and application of money and finance is major concern of the study. Similarly, the financial behavior of the individuals are affected by several psychological and situational factors according to the theories and practices as well. I find that, people does not necessarily always behave as they know and as they are confident about. There are several barriers in financial behavior in practice. However, Australian Securities and Investment Commission (2011) has mentioned that information and choice overload, complexity and uncertainty, time factors and pressures, over (and under) confidence, self-control and framing (i.e. how information is presented) are some of barriers of financial behavior of individuals. My study finds that financial literacy has short and long term effects.

I find that available categorizations of financial behavior have some practical limitations. I argue that categorizing the financial behavior of individuals right/wrong or best/worst are based on extreme evaluation of the phenomenon. Similarly, percentage scoring seems ad hoc that may not represent the practical classification of the financial behavior as well. It is also not that practicable to categorize the literacy on the basis of behavior, because the financial behaviors are affected by other factors as well, not only by the financial literacy. To overcome these limitations, I propose three comparative categories, i.e. good, moderate and weak financial behavior of individuals. I argue that financial behavior is person, context, time and place specific. However, my classification of behavior as good, moderate and weak rejects the extreme evaluation and tries to cover three possibilities of behavior, relatively. For example: if the researcher ask the participants about application of his/her borrowing with three possible answers, i.e. using credit in income generating business, using credit to maintain regular house expenditure and using the credit in marriage ceremony of daughter/son. The first option exhibits a good behavior, the second is moderate behavior and the third as a weak behavior. It is because the second answer is not so good but for low income people, maintaining the regular expenditure with their regular/limited income is challenging. In such, to spend in daily expenses than in marriage or any other family ceremony is moderate behavior. The last one is weak behavior, although it is also difficult to evaluate as bad or worst. From the income generating point of view, it is a weak behavior that may cause the person indebted in future. This is the case and compulsion of rural areas of poor economies like in Nepal. 
Next of my finding is financial education ultimately affects financial well-being of the individuals through a normal path, other things remaining the same. It means that if some assumptions and conditions are satisfied, financial education contributes financial literacy (financial knowledge and skill), thereby financial attitude and behavior and ultimately the financial well-being of the individuals. However, I am conscious about time lags, systemic barriers and the context where the individuals behave financially. So I argue that not always the behavior are affected by the knowledge and skill, neither it is a panacea of every financial problems of individuals. There are some arguments that the behavior also affects the financial literacy of individuals. The financial experience and practice also affect financial literacy.

In recent period, the financial literacy and behavior has emerging focus rather conventional wisdom. In conventional wisdom, the financial literacy is limited on financial understanding, doing regular saving, credit and investing function and prioritizing on inflation, compound interest and money matters. Buckland (2010) has opined that the financial literacy is required to understand in broader sense that the people are required to think some active, critical to the ongoing financial system, make some negotiation in financial market and engage some financial innovation as well. Search of financial alternatives, increasing negotiation skill to establish financial rights of financial consumers, making comparison on cost and return between and among service providers are some of new paradigm to develop as emerging concept on financial literacy. Similarly, Tisdell, Taylor and Forte (2013) have raised an agenda of financial (in)equity within the society as a new paradigm of discussion within financial literacy. Financial literacy is more relevant for low income, marginalized and minority people in society to uplift their financial position. Most of the previous studies are based on individual's agenda of using money in financial literacy is in positivistic manner. However, the studies have sidelined the issues of social aspects such as who controls the financial educational patterns in society, how to provide financial education to minimize social discrimination, how to include all the segments of people in societies into the financial mainstream for their financial empowerment etc. Forte (2012) argues that the financial education should also be understood with sociological perspective where the researchers can share their financial experiences with others so that the others also be benefitted. The development implication of financial literacy is also a contemporary issue.

My study has basic two side implications: for the policy makers and for the researchers. My study finds that the financial well-being of the people depends on improvement in financial behavior, whereas the behavior is contributed by financial literacy, other things remaining the same. Therefore, the financial literacy of people is important to improve. For this, developing formal educational curriculum from the schools is useful. For the other age group of people, the mass media, financial campaigns, informal training and financial counseling are useful. Moreover, in the financial market; financial fraudulence, financial misguidance, and monopolistic practices of financial intermediations are increasing. For this, consumer protection strategy through financial literacy is necessary to develop by policy makers. The future research is important to focus on how far the transmission mechanism works. There are more than three causal relationships demonstrated in the mechanism. The future studies are useful to test the relationship between and among the dimensions. For testing the relationships, the survey tools are better to develop by categorizing the financial behavior of individuals as good, moderate and weak ranking. The categorization also helps to design the survey tools, data collection and analysis.

\section{References}

Agarwalla, S. K., Barua, S. K., Jacob, J. \&Varma, J. R. (2012). A survey of financial literacy among students, young employees and the retired in India. Ahmadabad. Citi Foundation

Agarwalla, S. K., Barua, S. K., Jacob, J. \& Varma, J. R. (2015). Financial literacy among working young in urban India. World Development, 67, 101-109.

Ajzen, I. (1991). The theory of planned behavior. Organizational Behavior and Human Decision Processes, 50, 179-211

Ansong, A. \& Gyensare, M. A. (2012). Determinants of university working-students' financial literacy at the university of Cape Coast, Ghana. International Journal of Business and Management, 7(9), 126-133.

Atkinson, A. \& Messy, F. (2012). Measuring financial literacy: Results of the OECD / international network on financial education (INFE) pilot study. OECD Working Papers on Finance, Insurance and Private Pensions, No. 15, OECD Publishing. http://dx.doi.org/10.1787/5k9csfs90fr4-en 
Australian Securities and Investment Commission. (2011). Financial literacy and behavioral change. Report 230

Australian Securities and Investment Commission. (2014). National financial literacy strategy: ASIC

Bandura, A. (1971). Social learning theory. USA. General Learning Corporation.

Buckland, J. (2010). Are low-income Canadians financially literate? Placing financial literacy in the context of personal and structural constraints. Adult Education Quarterly, 60(4), 357-376.

Carpena, F., Cole, S., Shapiro, J. \& Zia, B. (2011). Unpacking the causal chain of financial literacy. World Bank working paper, 5798

Collins, J. M. (2010). Effects of mandatory financial education on low income clients. Focus, 27(1), 13-18.

Consumer Financial Protection Bureau. (2015). Financial well-being: The goal of financial education. Author.

Dahal, B. \&Uprety, U. (2015). Monitoring \&evaluation system: Measuring development results. Participation, 17(16), 5-21.

Dew, J. \& Xiao, J. J. (2011). The financial management behavior scale: Development and validation. Journal of Financial Counseling and Planning, 2(1), 43-59.

Fatoki, O. \& Oni, O. (2014). Financial literacy studies in South Africa: Current literature and research opportunities. Mediterranean Journal of Social Sciences, 5(20), 409-414.

Fernandes, D., Lynch, J. G. \& Netemeyer, R. G. (2014). Financial literacy, financial education and downstream financial behaviors.

Forte, K. S. (2012). Educating for financial literacy: A case study with a sociocultural lens. Adult Education Quarterly, 63(3), 215-235.

Fraczek, B. \& Klimontowicz, M. (2015). Financial literacy and its influence on you customers' decision factors. Journal of Innovation Management, 3(1), 62-84.

Hastings, J. S., Madrian, B. C. \& Skimmyhorn, W. L. (2013). Financial literacy, financial education and economic outcomes. Annu Rev Econom, 5, 347-373.

Hogarth, J, M., Beverly, S. G. \& Hilgert, M. (2003). Patterns of financial behaviors: Implications for community educators and policy makers discussion draft. Federal Reserve System Community Affairs Research Conference

Huston, S. J. (2010). Measuring financial literacy. The Journal of Consumer Affairs, 44(2), 296-316

Lusardi, A., Mitchell, O. S. \& Curto, V. (2010).Financial literacy among the young. The Journal of Consumer Affairs, 44(2), 358-380.

Lusardi, A. \& Mitchell, O. S. (2014). The economic importance of financial literacy: Theory and evidence. Journal of Economic Literature, 52(1), 5-44.

Lyons, A. C. (2005). Financial education and program evaluation: Challenges and potential for financial professionals. Journal of Personal Finance, 4(4), 56-68.

Madell, L. \& Klein, L. S. (2009). The impact of financial literacy education on subsequent financial behavior. The Journal of Financial Counseling and Planning, 20(1), 15-24.

Monticone, C. (2010). How much does wealth matter in the acquisition of financial literacy? The Journal of Consumer Affairs, 44(2), 403-422.

Organization for Economic Cooperation and Development. (2005). Improving financial literacy: analysis of issues and policies: OECD

Organization for Economic Cooperation and Development, International Network of Financial Education. (2012). Supplementary questions: Optional survey questions for the OECD INFE financial literacy core questionnaire. OECD/INFE

Parajuli, M. N. (2013). Realizing the existence of multiple forms of knowledge: A strategy towards seeing education for rural transformation. A conference paper presented in 4th Education for Rural Transformation (ERT) International Symposium. Bangkok, Thailand

Program for International Student Assessment. (2012). PISA 2012; Financial literacy assessment framework: Author

Ravikumar, T. (2013). Perceptions towards financial literacy in India. Research Journal of Social Science and Management, 2(9), 61-69.

Remund, D. L. (2010). Financial literacy explicated: The case for a clearer definition in an increasingly complex economy. The Journal of Consumer Affairs, 44(2), 276-295.

Robb, C. A. \& Woodyard, A. S. (2011). Financial knowledge and best practice behavior. Journal of Financial Counseling and Planning, 22(1), 60-70. 
Scheresberg, C. B. (2013). Financial literacy and financial behavior among youth adults: Evidence and implications. Numeracy, 6(2), 1-21.

Selcuk, E. A. (2015). Factors influencing college students' financial behaviors in Turkey: Evidence from a national survey. International Journal of Economics and Finance, 7(6), 87-94.

Shim, S., Barber, B. L., Card, N. A., Xiao, J. J. \& Serido, J. (2009). Financial socialization of first-year college students: The roles of parents, work, and education. Youth Adolescence, Springer. DOI 10.1007/s10964-009-9432-x.

Sucuahi, W. T. (2013). Determinants of financial literacy of micro entrepreneurs in Davao city. International Journal of Accounting Research, 1(1), 44-51.

Taft, M. K., Hosein, Z. Z., Mehrizi, S. M. T. \& Roshan, A. (2013). The relation between financial literacy, financial wellbeing and financial concerns. International Journal of Business and Management, 8(11), 63-75.

Tisdell, E. J., Taylor, E. W. \& Forte, K. S. (2013). Community-based financial literacy education in a cultural context: A study of teacher beliefs and pedagogical practice. Adult Education Quarterly, 63(4), 338356.

Willis, L. (Eds.). (2013). Financial education: Lessons not learned and lessons learned.CFA Institute

Xio, J. J., Chen, C. \& Chen, F. (2013). Consumer financial capability and financial satisfaction. Springer Science+Business Media, 113(3).

Xu, L. \& Zia, B. (2012). Financial literacy around the world: An overview of the evidence with practical suggestions for the way forward. A World Bank working paper, 6107 